\title{
A Paideia grega: aproximações teóricas sobre o ideal de formação do homem grego
}

Rosane Wanderscheer Bortolini ${ }^{1}$

César Nunes ${ }^{2}$

\section{Resumo}

A compreensão originária da paidéia grega sempre acompanha a formação de educadores e de pesquisadores em Educação. Trata-se de um tema que nos remete às origens da Educação e da compreensão do discurso filosófico e político sobre a Educação e suas dimensões. Apresenta-se a paidéia como princípio fundante voltado para o entendimento da formação social, política e cultural do povo grego a partir da problemática em torno da constituição histórica e filosófica dessa matriz Educacional. O objetivo foi abordar sobre os ideais de alguns filósofos e educadores que contribuíram para o pensamento do modelo grego de educação, entre outros aspectos, para a elaboração conceitual caracterizando e contextualizando-os em seu tempo e espaço histórico. Este artigo foi desenvolvido por pesquisa de caráter bibliográfico. Entre as contribuições desse estudo, estão os conceitos e fundamentos da arete e da paidéia, que direcionaram ou foram direcionados a pensar uma educação para a vida na pólis, portanto, para a vida em sociedade de maneira universalizada, por meio de uma educação com base na cientificidade, na virtude, na política. A essência da educação grega está na sua própria cultura e organização política que vai sendo evidenciada pela sociedade em praticamente três milênios.

Palavras-chave: Educação. Ética. Política. Sociedade.

\section{Resumen}

La comprehension orginaria de La Paideia griega siempre acompaña la formación de educadores y de investigadores en Educación. Se trata de un tema que nos remite a los orígenes de la Educación y de la comprensión del discurso filosófico y político sobre la Educación y sus dimensiones. Se presenta la paideia como principio fundante orientado hacia el entendimiento de la formación social, política y cultural del pueblo griego a partir de la problemática en torno a la constitución histórica y filosófica de esa matriz Educativa. El objetivo fue abordar sobre los ideales de algunos filósofos y educadores que contribuyeron al pensamiento del modelo griego de educación, entre otros aspectos, para la elaboración conceptual caracterizando y contextualizándolos en su tiempo y espacio histórico. Este artículo fue desarrollado por investigación de carácter bibliográfico. Entre las contribuciones de este estudio, están los conceptos y fundamentos de la arete y

\footnotetext{
${ }^{1}$ Pesquisadora da Universidade do Oeste do Paraná - UNIOESTE. E-mail: rosane.bortolini@unioeste.br

${ }^{2}$ Pesquisador do Grupo de Estudos e Pesquisas PAIDEIA/UNICAMP. E-mail: cnunes@unicamp.br
} 
de la paideia, que dirigieron o fueron dirigidos a pensar una educación para la vida en la polis, por lo tanto, para la vida en sociedad de manera universalizada, a través de una educación con base en la ciencia, en la virtud, en la política. La esencia de la educación griega está en su propia cultura y organización política que va siendo evidenciada por la sociedad en casi tres milenios.

Palabras-clave: Educación. Etica. Política. Sociedad..

\section{Introdução}

sse artigo tem o intuito de apresentar alguns aspectos
importantes da cultura grega que contribuíram para a
constituição dos modelos educacionais que se sucederam no decorrer do processo histórico civilizatório. Ressalta-se, no entanto, que o objetivo é presenciar o lugar que alguns filósofos gregos ocuparam e ocupam na história da pedagogia, que não se separa da organização social, cultural e política da pólis. Trata-se de um estudo histórico-político.

Partindo do pressuposto que as dimensões do conhecimento, historicamente acumulado pela humanidade são temporais, portanto, pertencente a um campo teórico ainda insignificantemente conhecido e geralmente estimado, busca-se por meio de estudos em torno do legado grego evidenciar a importância social e cultural para as culturas que os sucederam, por meio dos registros e evidencias que se têm sobre a educação e formação do homem, parte-se do estudo sobre a paidéia antiga como o modelo de educação grega, que certamente não corresponde ao sentido que é tem sido atribuído ao termo educação nos anos que se seguiram. A paidéia grega tinha como objetivo a formação integral do homem para a vida em sociedade.

Um aspecto importante a destacar sobre a paidéia antiga, está ligada ao fato que tem sido afastada das tradições das pesquisas em educação no Brasil. As produções científicas brasileiras têm privilegiado ideologias dominantes, carregadas de ideais sociais, políticos, econômicos e culturais, que possuem "caráter hermético e elitista", produzem e reproduzem "marginalizações históricas de amplas camadas sociais da escola", além disso exercem "a 
hegemonia totalitária de pedagogias excludentes, antipopulares e antidemocráticas" (NUNES, 2000, p.67).

Os gregos, entendendo aqui a rica civilização helênica que floresceu numa região chamada Ática, no Mar Mediterrâneo, entre os séculos VIII e II a.C, inventaram ricas e maravilhosas coisas e criaram muitas das instituições que ainda perduram em nossa sociedade. Sua criação original atravessou o tempo e, ainda hoje, organiza e orienta nossa vida social, cultural e civilizatória. Sabemos que para estudar uma determinada dimensão da vida devemos ir às origens, ao fundamento primeiro, às condições de nascimento de uma determinada prática ou de um conceito. Esse método chama-se de "arqueologia", isto é, buscar os sentidos primordiais das palavras e de seus contextos.

Assim sendo, também será preciso voltar aos gregos, aos estudos e obras de homens como Sócrates (469 - 399 a. C.), Platão ( 428 - 347 a.C.) e Aristóteles ( 384 - 322 a.C.), para ficar entre os clássicos, se quisermos entender inicialmente os conceitos de Ética e de Política. Esse artigo quer inspirar igualmente uma reflexão inicial sobre os sentidos originais das palavras e das práticas sociais reconhecidas como a Ética e a Política, de modo que consigamos entender bem esses conceitos, tirando deles esse suposto grau de complexidade que, muitas vezes, estão presentes em conceitos fundamentais para nossa vida e nossa cultura, dificultando nosso entendimento.

É preciso definir a premissa fundamental, a dimensão da educação. Educar implica em reconhecer que a condição humana é aprendida, que é historicamente produzida, que a educação é um projeto definido no tempo e no espaço humano e natural. Significa formar o homem, engendrar, isto é, fazer, produzir, a pessoa humana, para a vida em sociedade. Implica em reconhecer que a tarefa de fazer-se homem, a hominização de si, renova-se a cada nascimento, a cada geração, a cada criança. Somos seres sociais, animais políticos, entes sensíveis, coabitantes da mesma terra, viajantes da história, somos promessas e penhores dos futuros incertos. O pesquisador e 
amigo SAVIANI (2006) assim define magistralmente essa dimensão educacional:

[...] o trabalho educativo é o ato de produzir, direta e intencionalmente, em cada indivíduo singular, a humanidade que é produzida histórica e coletivamente pelo conjunto dos homens. Assim, o objeto da educação diz respeito, de um lado, à identificação dos elementos culturais que precisam ser assimilados pelos indivíduos da espécie humana para que eles se tornem humanos e, de outro lado e concomitantemente, à descoberta das formas mais adequadas para atingir esse objetivo. (SAVIANI, D. 2006, p.13)

Nascemos numa determinada sociedade, somos tributários ou herdeiros de uma cultura ou civilização. Toda geração terá que repassar, para a geração posterior, os símbolos materiais e culturais da marcha histórica da humanidade. E, nesse vertiginoso porvir dos tempos todos buscamos inventar, tanto quanto desejamos construir, marcar, ou ainda procuramos criar e reproduzir os sinais e os símbolos que nos garantissem o reconhecimento da caminhada, a proximidade dos pontos seguros, o rumo, a direção. Não se faz esse caminho sem a ajuda dos outros, dos tempos passados, como faróis a indicar a trilha dos tempos futuros. Essa é a identidade da Ética, uma pergunta e uma indagação que os gregos inventaram e que perpassa os tempos inteiros, a refazer-se em cada pessoa e em sua geração: qual é o sentido maior de minha existência, qual é o ideal melhor para nossa vida pessoal, particular e coletiva? Aristóteles definiu a propriedade maior desse conceito. A palavra "Éthika", em grego, deriva de "Ethos" ou "Ethikos", que significaria "morada, casa, esteio da casa, lugar de viver, regras de organizar a casa", referindo ao esteio central que erigia a casa grega primitiva. Essa palavra assume o sentido de "aquilo que sustenta minha morada, minha moradia, minha vida doméstica". De um sentido prático e físico para um sentido simbólico e moral!

A Ética é o campo de construção das questões fundamentais da vida humana, de cada vida humana e dos sentidos postos para os tempos históricos e para os destinos coletivos. Trata-se de uma "ciência prática", na feliz definição de Aristóteles, cuja inspiração seria a de conduzir a natureza humana ao equilíbrio, à excelência, entendida como uma luz interior a 
propor e clarear caminhos e mediações para a conquista da felicidade. Essa concepção eudaimonista (prazerosa, voluntária, que traz felicidades) e pragmática permanece como distinção da reflexão ética: como deveremos agir para conquistar a possibilidade de fazermos da vida uma expressão de felicidade, de harmonia, de equilíbrio, de temperança e de busca da igualdade?

A Ética seria a reflexão sobre esse "dever-ser" que inspiraria nossas condutas e nossas ações morais. Aqui a Ética seria o horizonte inspirador da moral, portanto, sua fiança e seu penhor maior! Já a Política seria a busca de elementos coletivos para a conquista da felicidade. Os homens, seres ou entes de natureza política ou associativa, deveriam encontrar formas racionais e elevadas, virtuosas e expressivas, para construir uma sociedade sobre premissas de paz, de respeito às diversidades das pessoas e de seus universos, de cultivo do diálogo, de buscas do equilíbrio e de esperanças de vida plena sustentadas sobre sentidos singulares e sobre ações comuns.

A Ética e a Política seriam as ciências práticas para se conquistar essa felicidade, inspiração de nossa natureza racional e associativa, no campo particular e no campo coletivo. E como conseguiríamos articular a Ética e a Política com a Educação? Para Aristóteles a PAIDEIA, a educação plena e integral do homem, é o processo de desenvolvimento subjetivo e social de cada pessoa, a partir de sua natureza ética e de sua identidade política. E, por vezes, ele igualmente aponta a dimensão estética, isto é, o sentido e desejo de conquistar o máximo do bem e do belo da vida, o que ele chamou de sumo bom (o máximo da bondade, o ideal ético de bondade, de ser bom) identificando-se com o sumo bem ( o máximo da perfeição formal, o ideal de ser plenamente realizado) e ambos se revelando no sumo belo ( o máximo da beleza estética, da realização perfeita do ser da cada coisa ou pessoa). Ser ético, ser político e ser estético seria isso: ser uma pessoa humana plena! Somente pela educação desenvolvemos nossa natureza humana, ética, estética e política. Educar, portanto, é proceder o desenvolvimento humano, humanizar, criar e formar para a cidadania, a politeia, a educação para viver bem na polis. Trata-se de ser sujeito e buscar 
superar o assujeitamento alienado que a sociedade de classes produz. É preciso questionar essa dependência construída das tecnologias de comunicação atuais. Não significa abandoná-las, mas sim criar formas de apropriação, criteriosas, equilibradas, éticas! ADORNO (2001) definiu essa forma de padronização ideológica e comportamental das sociedades atuais como a produção da "Indústria Cultural".

[...] O poder que a 'indústria cultural' exerce sobre os consumidores está justamente na sua capacidade de conferir um caráter de divertimento para tudo. Assim os instrumentos da indústria cultural (televisão, rádio, revista e cinema comercial; os meios de comunicação de massa, redes sociais, internet, etc) tornam-se válvulas de escape para os trabalhadores, as camadas médias e suas famílias, que exercem tarefas mecanizadas e cansativas. O lazer oferecido pela indústria cultural é, então, um lazer compensatório, para que todos (as) possam divertir-se um pouco e voltar ao trabalho em condições de suportá-lo por mais um período de tempo. (ADORNO, 2001, p.35)

Vivemos tempos difíceis, como são normalmente considerados os tempos de longa transição social, produtiva e cultural. Estamos no meio de uma revolução tecnológica e material. Mas não podemos deixar de lado as referências de nosso agir humano: A Ética, a Estética e a Política. O governo das coisas humanas é nosso desafio. A Ética sempre se articula com a Ciência e a Política, em seus sentidos mais amplos. As descobertas científicas impõem necessárias reflexões éticas e a Ética exige da ciência alguns parâmetros e até necessita lembrar os seus limites. Essa relação é histórica, é política, e dependerá das interlocuções sociais qualificadas, sensíveis e esclarecidas. As pesquisas sobre as células-tronco são irreversíveis, por exemplo, haveremos de constituir parâmetros para seu manejo e aplicabilidade a todas as formas de promoção da vida! Muitas pessoas dizem que ética não se aprende na escola, mas em casa. Tenho lutado para articular a escola, a sociedade e a família, a unidade parental básica, em amplo processo de transformações institucionais e culturais.

Há diversas e diferentes dimensões dessa concepção de Ética. Há uma Ética dominante na sociedade, há expressões de algumas considerações éticas no trabalho, na cultura social, nos Meios de Comunicação, nas Tecnologias de Informação e Comunicação e, por conseguinte, na família. A 
unidade parental básica, que é a definição sociológica de família, hoje diversa e transformada pelos novos direitos e pelos novos sujeitos sociais, é a primeira educação. E, se a ética é uma dimensão social, ela terá que ser ensinada, testemunhada e exemplarmente vivida pelos pais diante e em conjunto com seus filhos. Uma ética que atente para educação afetiva, de modo a constituir uma conduta de cuidado com o corpo, com a sexualidade, com a beleza, com a privacidade. A forma com que os jovens, os adolescentes e crianças hoje lidam com os espaços sociais, com as tecnologias de comunicação, demonstra relativo afrouxamento de valores. Mas a escola também é uma instituição central na formação da pessoa. A Ética está presente nos valores que inspiram as relações na escola, na organização do trabalho pedagógico, no acolhimento dos alunos e estudantes, no trato com os funcionários, com os pais, com a comunidade, com o próprio espaço e acervo escolar, com o currículo. A Ética na família e a Ética na escola têm distinções e similaridades, mas a base de ambas deve ser a mesma: a Vida, a humanização das relações, a sensibilidade, a elevação estética, a Verdade, o Amor, o cuidado de si e dos outros, a preservação da natureza, o respeito à diversidade da natureza e das pessoas!

O poeta Maikovisky escreveu: "(...) não poderá sustentar as asas quem não teve raízes profundas". Sem a Ética, caminho da felicidade particular, sem a Política, espaço da felicidade coletiva, a condição humana não se realiza.

A palavra paidéia só surge no século $\mathrm{V}$, com o significado de "criação de meninos", sem relação inicial ao valor atribuído ao termo mais tarde. Contudo "[...] não se pode utilizar a história da palavra paidéia como fio condutor para estudar a origem da educação grega." (JAEGER, 2003, p. 25). "O essencial da história da formação grega é antes o conceito de arete que remota aos tempos mais antigos" (JAEGER, 2003, p. 25). A concepção de arete, não tem uma tradução específica para a nossa língua na atual conjuntura do século XXI, para Jaeger o termo se aproxima mais do sentido de virtude, com centralidade no ideal de educação da época. Por esse motivo, o entendimento da essência da formação do homem grego está na 
própria compreensão dos conceitos por eles vivenciados na cultura, na política e na sociedade grega como um todo, a partir do seu tempo e contexto.

\begin{abstract}
$\mathrm{O}$ conhecimento que Sócrates identifica à arete é a episteme e não a doxa. E essa episteme - que não pode ser ensinada - não constitui uma ciência sobre coisas ou informações voltadas para a obtenção de prestígio ou de riqueza: é o conhecimento de si mesmo, a autoconsciência despertada e mantida em permanente vigia. Bom é, assim, o homem auto construído a partir de seu próprio centro e que age de acordo com exigências de sua alma - consciência - seu oráculo interior finalmente decifrado (SOCRATES, 2004, p.30).
\end{abstract}

A arete grega se expressa, antes do surgimento do termo Paideia como o ideal na educação do homem grego. Segundo Jaeger (2003) a palavra que mais se aproxima do termo arete é uma virtude com o sentido de exprimir a conduta cortez e ao heroísmo guerreiro. A presença do conceito de arete é facilmente observável nas epopeias de Homero. Para o educador Homero a arete estava relacionada a moralidade e a espiritualidade, porém tais qualidades estão intimamente ligadas.

Além do ideal do homem, o espirito aristocrático exercia forte influência na sociedade grega, a arete tornava-se para os gregos a excelência humana e atributo da nobreza. Para Fonseca (1998) a cultura grega está presente nas atividades racionais e nos ideais dos séculos que se advieram, afirma ainda que as civilizações posteriores são herdeiras e fiéis devotos do legado cultural grego. A cultura europeia ocidental, que tem influenciado diretamente e indiretamente de forma global as demais culturas, é fruto da intersecção de culturas que exercem forças significativas, que são os pensamentos com raízes nos postulados grego, assim como a legislatura com influência do direito romano e a própria religião com princípios cristãos. O mundo grego exerceu papel importantíssimo no contexto histórico educacional. Segundo Wandscheer (2005), os gregos tinham como finalidade maior a formação de um tipo elevado de homem, buscavam concretiza-lo por meio da Paideia.

É pelo caráter natural e universal que os gregos atribuem a educação um sentido moral e prático, preocupados com a formação integral do homem, 
apresentam o humanismo como princípio. O humanismo não se desvincula do ceticismo e do relativismo epistemológico. A Paideia sob forma de cultura, é considerada por Jaeger a herança da Antiguidade, foi o conjunto de uma obra criadora que os outros povos se fizeram herdeiros. "Sem a concepção grega de cultura não teria existido a 'Antiguidade' como unidade histórica, nem o 'mundo da cultura' ocidental (JAEGER, 2003, p.3) ”.

A própria civilização grega arcaica iniciada por volta de três milênios a.C foi formada por uma diversificação de etnias e culturas. Entre os povos que formaram a civilização grega estão em Esparta: os dórios (cidadãos espartanos), periecos (habitantes originais), hilotas (escravos); e em Atenas os considerados cidadãos eram os filhos de Atenas e os metecos estrangeiros que pagavam impostos e participavam do exercito ateniense, mas não da vida política. A formação geográfica da Grécia favoreceu a formação de reinos isolados e independentes, os quais aliavam-se sempre que necessário, além disso, desenvolveram intercâmbios comerciais e sociais, desenvolvendo uma espiritualidade comum, um alfabeto e o exercício da mitopoietica (CAMBI,1999).

Pode-se afirmar que a cultura grega teve papel revolucionário no contexto da história da educação humana. É impossível descreve-la em poucas palavras, pois não representam ou representaram um conjunto de ideias abstratas, reflete a própria história da Grécia, sua realidade vivenciada. No entanto, vale ressaltar que no princípio, em estágios primitivos da cultura grega, não havia a clareza da finalidade da formação de um modelo elevado de homem, à medida em que o tempo avançava esse ideal de homem vai se gravando na consciência da cultura grega, com clareza cada vez maior (WANDSCHEER, 2005), ao afirmar que

\footnotetext{
A ideia de educação representava, desse modo, o sentido de todo esforço humano. O conhecimento próprio, a inteligência clara do Grego encontrava-se no topo do seu desenvolvimento. (IBID, 2005, p.17)
}

Vale ressaltar que a formação do homem integral, a Paidéia, é característica fundante da cultura dos gregos antigos. A educação grega, nesse contexto, em especial a educação ateniense não terminou com a tomada da Grécia pelos romanos, pelo contrário houve absorção da cultura grega pelos 
romanos, que passou a ser chamada pelos historiadores como cultura grecoromana.

Fonseca (1998) destaca que Roma helenizou-se e posteriormente se romanizou, para explicar a universalização da cultura grega pelos romanos, acrescenta ainda que tais influências no modo de conceber o que venha a ser educação, as suas práticas, os conteúdos e os próprios ideais educativos são heranças da cultura grega. Nesse sentido, a relação que os gregos estabelecem com a educação perpassa, pode-se dizer que milênios, que não só influenciam modelos educacionais, como também direcionam os caminhos da pedagogia a adotar.

Há períodos importantes na configuração da educação grega, que se inicia com o período pré-homérico, na constituição do povo grego, entre 2500 a 1100 a.C; o período Homérico, marcado pelos poemas e epopeias, entre as mais conhecidas Iliada e Odisseia 1100 a 800 a.C; o período arcaico com a formação das cidades-estados de 800 a 500 a.C; o período clássico com os filósofos gregos Sócrates, Platão e Aristóteles de 500 a 400 a.C; e o período helenístico marcado pela decadência da Grécia de 336 a 146 a.C. No entanto, a importância dessa demarcação da temporalidade e da localidade histórica serve como reflexão do objeto em questão, um período não anula o outro, muito pelo contrário, serve para facilitar a compreensão da formação do ideal de educação grega, num processo histórico, social e cultural longo e dialético (na concepção marxista).

O período homérico e arcaico se distingue por meio de uma educação do exemplo, tinha como educador Homero no século $\mathrm{X}$ a.C com obras historicamente conhecida como Odisseia e Iliada e Hesiodo no século VIII a.C com as obras Teogonia e Trabalhos e Dias, tornaram-se essenciais para a educação grega arcaica. A arete, nesse contexto, está relacionada a formação do herói, destinada a juventude aristocrata. Os poemas homéricos constituíram por séculos os ideais educativos da classe dominante.

A educação grega arcaica por meio da poesia, utilizava-se da rapsódia, ou seja, utilizava-se de poesias decoradas, que constitui Rapsodo, como aquele que decora a poesia, isso ocorre como um processo intencional, que é 
educar para a "virtude, para a admiração dos heróis e de seus feitos. Essa educação moral era a sustentação da educação aristocrática ateniense" (NUNES, 2017, p.3,).

Com o início da constituição da pólis entre VIII e VII a.C, inicia-se uma nova fase, a organização do Estado político grego vai se modificando na medida em que a mesma vai se constituindo em cidade-estado com forte unidade espiritual, no sentido religioso e mitopoietico. Outra questão que surge com a pólis é preocupação com o problema educativo como esfera educativa e civilizatória (CAMBI, 1999).

No livro IV, da República de Platão, Sócrates em diálogo com Admanto relata sobre prescrições simples de tarefas para que a cidade se desenvolva:

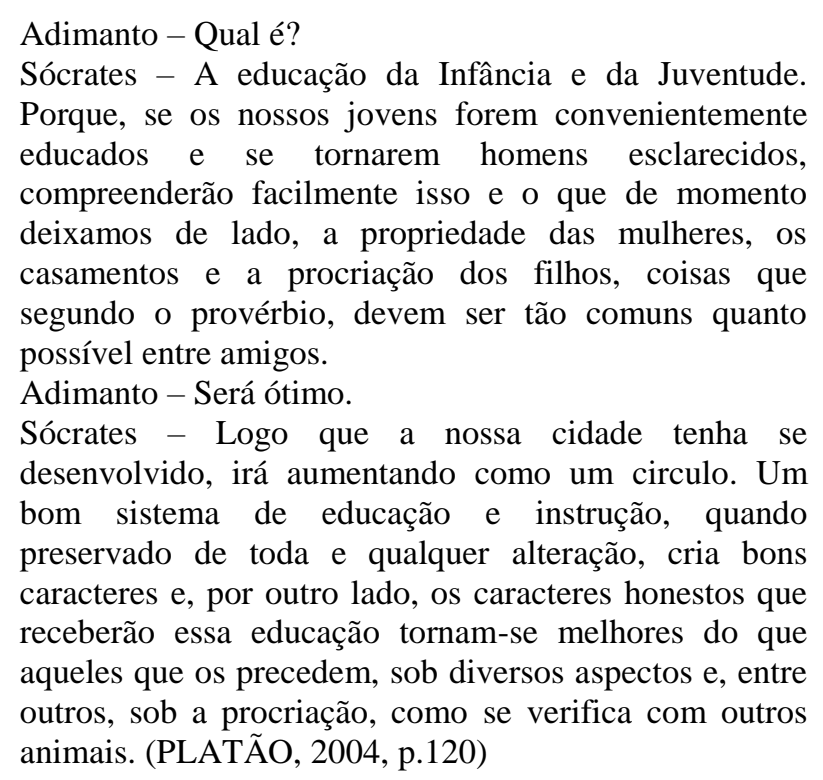

Jaeger (2003, p. 753) ao enfocar a dimensão platônica "como fonte do sentido mais profundo da existência humana" cita Jean-Jacques Rosseau como um autor que soube discernir, aproximando-se com sabedoria dos ideais do "Estado platônico, ao declarar que a República não era uma teoria do Estado, como pensavam aqueles que só julgavam os livros pelos títulos, mas sim o mais fabuloso estudo jamais escrito sobre educação."

A alegoria da caverna expressa no livro VII da República de Platão, possui fabulação religiosa e conotação política, pois aquele que consegue se liberta das ilusões e enxerga a verdade, possui sabedoria, deve liderar para libertar os demais prisioneiros que enxergam apenas as sombras, “é o filósofo- 
político, aquele que faz de sua sabedoria um instrumento de libertação de consciências e justiça social, aquele que faz da procura da verdade uma arte...” (PLATÃO, 1991, p. XXI)

A pólis, devido a diversidade sócio cultural das cidades estados, passa a ser um centro de uma comunidade pedagógica caracterizada por atividade de teatro, tragédia e comédia. Um bom exemplo é a exposição ao ridículo de alguma forma de comportamento não aceito, por meio do teatro.

A preocupação com o problema educativo que surge na Grécia arcaica, é, contudo, predominante evidenciado em Atenas, no século V a.C, segundo Fonseca $(2005$, p.2) principalmente com o surgimento "dos Sofistas que se apresentam com novas propostas e soluções educativas, com um novo plano de estudos e como outros e novos mestres, em nada semelhantes aos do passado."

O papel que a educação adquire na Grécia clássica, em especial em Atenas tem papel central, burocrático, porem democrático, tornando-se motivo e necessidade de debate, tendendo-se a universalizar-se para além dos limites da pólis. Em Esparta, diferentemente de Atenas, prevalece um modelo de Estado totalitário (CAMBI,1999).

[...] também a cultura após a adoção do alfabeto iônico, totalmente fonético (em 403) que se tornou comum a toda a Grécia, teve um esplendido florescimento em todos os campos: da poesia ao teatro, da história à filosofia. No século V Atenas tinha cerca de 300 mil habitantes e exercia um influxo sobre toda a Grécia: tinha a necessidade de uma burocracia culta que conhecesse a escrita (CAMBI, 1999, p. 84).

Platão e Aristóteles, no século IV a.C na busca por uma ressignificação da vida na pólis por meio da razão humana, procuram definir alguns fundamentos éticos e políticos. A educação que se centrava na formação do homem aristocrata ateniense, passa a receber “interposição dos filósofos Platão e Aristóteles. O fundamento desta educação aristocrática girava ao redor do conceito de arete ou de virtude" (NUNES, 2017, p.3).

A educação dos gregos passa a exercer na humanidade, um papel natural e também universal, entendem ainda que se leva muito tempo para compreender o real papel da educação na vida e na sociedade, seja por 
aqueles que a praticam ou por aqueles que a recebem. $\mathrm{O}$ surgimento da cidade-estado, trouxe consigo novas indagações filosóficas. As invetigações que decorriam dos problemas do mundo com os pré-socráticos, passam a dar espaço a investigações sobre a essencia e a existencia do ser, como identidade do homem da pólis, como tese central da filosofia grega classica. A primeira fase, da educação grega no período clássico era concedida a juventude masculina que frequentavam "a escola e a palestra, onde eram instruídos através da leitura, da escrita, da música e da educação física, esse período era marcado pela presença de três instrutores: o paidotribes (mestre), o kitharistes (instrutor de música), o gramatistes (professor de gramática)" (CAMBI,1999, p.83). Caracterizada, por preceitos de moralidade e prudência, a educação grega em seu conteúdo reveste-se de mandamentos, apresenta-se ainda como comunicação para o desenvolvimento de aptidões relacionadas a profissionalização, a techne (JAEGER, 2003).

A filosofia Clássica inaugura na pólis, a busca por "uma teoria da educação de modo a justificar uma ordem entre as práticas educacionais e as finalidades expressas e esperadas para a educação" (NUNES, 2000, p. 61). A epistéme, ou seja, a ciência, passa a ter necessidade de articulação com a prática, com a técnica.

Os gregos distinguem educação de formação, dada as especificidades de cada uma. O termo formação geralmente é associado a aprendizagens externas e atitude interior, as quais se manifestam numa forma integral no homem, e que só termina com o termino da existência humana. Platão esboça nas leis que "a essência de toda a verdadeira educação ou paidéia", é baseada na "arete que enche o homem do desejo e da ânsia de se tornar um cidadão perfeito e o ensina a mandar e obedecer, sobre o fundamento da justiça” (JAEGER, 2003, p. 147).

Entendemos que "A educação ética e política era considerada como traço fundamental da essência da verdadeira paidéia." "A paidéia grega encerra a primeira forma sistematizada de uma filosofia da educação" (NUNES, 2000, p. 61-62) 
Aos sofistas, a guinada antropológica do processo educativo, fundando a techne da formação por meio da linguagem, ao filósofo Sócrates atribui-se a dramaticidade e a universalidade do processo, que envolve os fundamentos - ab imis - e a busca de um daimon como ativação de uma identidade, através da "dialética que produz a universalização do indivíduo pela discussão racional e pelo seu processo sempre renovado, a fim de atingir a virtude mais própria do homem, que é o 'conhece-te a ti mesmo" " (CAMBI, 1999, p. 86, 87). As primeiras noções de paidéia são evidenciadas desde os primórdios da cultura grega, passa do ethos e da práxis apenas, para o pensamento da educação como epsteme, atingindo as várias culturas posteriores.

Para Platão, assim como para Aristóteles, a arte de educar, a paidéia, é uma virtude com caráter eminentemente político (WANDSCHEER, 2005). Segundo Cambi (1999) o pensamento da educação como episteme, apresenta uma maior complexibilidade dos problemas educativos que se encontram fora da localidade, do determinismo cultural e ambiental, apresentando-se no processo de universalização racional, coloca em evidência a noção de paidéia que por milênios foi a base das reflexões educativas, reconstituindo-se como paidéia cristã, humanística e posteriormente como Bildung.

\section{Considerações parciais}

A paidéia grega, em seus vastos séculos de composição conceitual e histórica, é considerada revolucionária no processo de educação humana. Não é possível descrevê-la em poucas palavras, devido a sua complexidade. A paidéia não é formada por ideias abstratas mas reflete a própria história do mundo grego, a realidade concretizada numa determinada temporalidade e localidade. O objetivo maior, era a formação de um tipo elevado de homem.

É importante destacar que apesar da periodização que alguns pesquisadores estabelecem ao estudar a história, não se pode cair no equivoco estabelecendo rupturas históricas positivistas, deve-se, no entanto, pensá-la 
de forma dialética (conceito marxista). Um exemplo prático é o pensamento ético ao qual Platão e Aristóteles baseiam-se, há muitos aspectos fundamentados na ética aristocrática vivenciados Grécia Arcaica. Assim como muitos gregos, de diferentes tempos, foram influenciados pelo educador Homero, elaborando suas teorias e conceitos influenciados por seu modelo de educação.

Para Sócrates a educação deveria ter na base a arete, como uma missão política, de valorização da virtude cívica. A educação para Platão, deveria ser vista e encarada como um trabalho de edificação da própria cidadeestado. É evidente que cada filosofo, ao seu modo contribui para a formação da concepção grega de educação, que vai se formando historicamente por meio da própria História da Cultura Grega.

Pode-se afirmar que os verdadeiros representantes da Paidéia grega são os filósofos e educadores, os quais exercem a ação educadora por meio de episteme da práxis, buscando uma formação integral do homem virtuoso, ético e livre. Só assim se constitui a base da cidade-estado que se leve a uma perfeição, dirigido pelo filósofo que saberá exercer o poder político de modo a trazer alegrias e felicidades para a pólis.

\section{Referências}

CAMBI, Franco. História da pedagogia. Trad. Álvaro Lorencini. São Paulo: Ed. UNESP, 1999.

FONSECA, Maria de Jesus. A Paideia Grega revisitada. Millenium, n. 9, jan. 1998. Disponível em: < http://www.ipv.pt/millenium/esf9 mjf.htm>. Acesso em: 15 de jul. de 2017.

GROSS, Renato. Paidéia: as múltiplas faces da Utopia em Pedagogia. Campinas, SP: Tese de doutorado, UNICAMP, 2005. Disponível em: $<$ http://repositorio.unicamp.br/bitstream/REPOSIP/252977/1/Gross_Rena to_D.pdf>; Acesso em: 18 de jul. de 2017.

JAEGER, Werner. PAIDEIA: a formação do homem grego. São Paulo: Martins Fontes, 2003.

MESQUIDA, P., WANDSCHEER, R. A Paidéia freireana: a utopia da formação como prática da liberdade. Artigo cientifico: ISBN 857292147-8; 2005 
NUNES, César Apareccido. Da Filosofia do Amor ao Amor à Filosofia. Librum Edições \& Editora Brasílica, Campinas, 2017, p.1-69.

NUNES, César Apareccido. As origens da articulação entre filosofia e educação: matrizes conceituais e notas críticas sobre a Paideia crítica. In: LOMBARDI, José Claudinei. (Org). Pesquisa em Educação: história, filosofia e temas transversais. Campinas, SP: Autores Associados, 2000, (Coleção HISTEDBR).

OLIVEIRA, José Silvio de. A Paidéia Grega: a formação do omnilateral em Platão e Aristóteles. Tese de Doutorado, São Carlos, UFSCar, 2015. Disponível em:

<https://repositorio.ufscar.br/bitstream/handle/ufscar/2370/6763.pdf?seque nce $=1$ \&isAllowed $=y>$. Acesso em: 16 de jul. de 2017.

PLATÃO. A República. São Paulo: Nova Cultural, 2004.

PLATÃO. Diálogos: o Banquete, Fédon, Sofistas, Político. São Paulo: Nova Cultural, 1991.

SAVIANI, Dermeval. Pedagogia Histórico-Crítica. Editora Autores Associados, Campinas, 2006.

WANDSCHEER, Rosane. Paidéia e Utopia na Pedagogia da Libertação de Paulo Freire. Dissertação de Mestrado, Curitiba, PUCPR, 2007.

Disponível em:

<http://www.dominiopublico.gov.br/pesquisa/DetalheObraForm.do?select_ action=\&co_obra=82373 > . Acesso em: 14 de jul. de 2017. 